\title{
A Combination of Ultrasonography and Real Time Elastography (RTE) in Differentiating benign and Malignant Thyroid Nodules, Does It Help?
}

\begin{abstract}
Shubham Gaur ${ }^{1}$, Sudhir Navale², John D'souza ${ }^{3}$, Priscilla Joshi ${ }^{4}$
${ }^{1}$ SR, Department of Radiodiagnosis, Bharati Hospital, Bharati Vidyapeeth Deemed University Medical College, ${ }^{2}$ Associate Professor, Department of Radiodiagnosis, Bharati Hospital, Bharati Vidyapeeth Deemed University Medical College, ${ }^{3}$ Professor, Department of Radiodiagnosis, Bharati Hospital, Bharati Vidyapeeth Deemed University Medical College, ${ }^{4}$ Professor, Department of Radiodiagnosis, Bharati Hospital, Bharati Vidyapeeth Deemed University Medical College, India
\end{abstract}

Corresponding author: Dr. Sudhir Navale, Associate Professor, Department of Radiodiagnosis, Bharati Hospital, Bharati Vidyapeeth Deemed University Medical College, India

DOI: http://dx.doi.org/10.21276/ijcmsr.2019.4.3.40

How to cite this article: Shubham Gaur, Sudhir Navale, John D'souza, Priscilla Joshi. A combination of ultrasonography and real time elastography (RTE) in differentiating benign and malignant thyroid nodules, does it help?. International Journal of Contemporary Medicine Surgery and Radiology. 2019;4(3):C182-C186.

\section{A B S T R A C T}

Introduction: Thyroid nodule is an abnormal growth of cells within the thyroid gland which can be benign or malignant. 5\%$15 \%$ of thyroid nodules are malignant. Aim of this study was to evaluate the diagnostic accuracy of Grey scale ultrasonography, elastography and a combination of both and compare the same with histopathology, to reduce unnecessary FNACs of benign nodules. Settings and Design: 50 patients were evaluated in a tertiary referral hospital. This was a prospective, observational study.

Material and Methods: TIRADS classification was used for evaluating patients using ultrasonography. Tsukuba scoring was used for qualitative sonoelastographic scoring. FNAC reports/histopathology reports were compared.

Results: Sensitivity, specificity, NPV and PPV in differentiating benign and malignant nodules were 90, 97, 90, and 97\% respectively. Sensitivity and accuracy of the combination was statistically superior to the gray-scale alone. The accuracy of USG alone was $94 \%$ and combination of elastography and grey scale USG was $96 \%$. The ROC curve analysis for elastographic strain indices revealed area under curve to be 0.9 . The cut-off value was 0.8 . The sensitivity and specificity was $100 \%$ and $94.9 \%$ respectively with positive likelihood ratio of 19.5 . Nodules that scored 1 and 2 on elastography could be safely monitored without need for FNAC. We considered that $35 \%$ nodules grow in time and the reduction of FNACs based on our study was $39 \%$.

Conclusion: Study showed significant sensitivity and accuracy of ultrasonography and sonoelastography in differentiating benign from malignant nodules. Sonoelastography further increased the sensitivity and specificity when done in conjunction with ultrasonography.

Keywords: Ultrasonography, Real Time Elastography (RTE), Malignant Thyroid Nodules

\section{INTRODUCTION}

The thyroid gland helps in maintaining the normal growth and activity of humans. It is one of the major secreting organs having an auto-regulatory mechanism.

A thyroid nodule is an abnormal growth of cells within the thyroid gland and can be benign or malignant.

In the adult population thyroid nodules have a prevalence of $4 \%-7 \%$ and non-palpable thyroid nodules are frequently detected on ultrasound. Most of the thyroid nodules are smaller than $1 \mathrm{~cm}$ and thus not clinically important. The risk of malignancy in thyroid nodules is generally between $5 \%$ $15 \%$. Current management guidelines require diagnostic USG to be performed in all patients with thyroid nodules and needle FNAC should follow in those having potentially malignant nodules. ${ }^{1}$ A cost-benefit diagnostic strategy needs to be followed.

Ultrasound is easily available and also effective in detecting thyroid nodules. Various USG findings help differentiate benign from malignant thyroid nodules. However, the sensitivity, specificity, negative and positive predictive values for these criteria vary from study to study. Hence, the need for a modality that incorporates such a feature. Tissue elastography meets this requirement.

Over the last two decades, various methods have been proposed to estimate tissue elasticity with diagnostic ultrasound. In general, these methods can be categorized into two groups based on how the tissue is stressed. The first category, called strain elastography or the static method which uses quasi-static compression and estimates resulting tissue strain. ${ }^{2}$ The other category is shear wave elasticity imaging, which generates low-frequency shear waves in the 
target tissue by employing focused acoustic beams. We used the former technique for our study.

The main goal of this study was to prospectively evaluate the diagnostic accuracy of grey scale ultrasonography and elastography as well as a combination of both methods and compare the same with histopathology.

\section{MATERIAL AND METHODS}

This was a prospective, observational and quantitative study. 50 Patients referred to the department of Radio diagnosis and Imaging of Bharati medical college and hospital for suspicious nodules in neck region were evaluated for a period of 2 years.

\section{Inclusion Criteria}

- All patients above the age of 18 years.

- Patients selected included those who satisfy the FNAC criteria set forth according to Bethesda guidelines (A nodule threshold diameter of more than $1 \mathrm{~cm}$ to perform thyroid FNACs).

\section{Exclusion Criteria}

Pre diagnosed and surgically treated patients were excluded. Observations were based on the findings of ultrasonography and sonoelastography.

Technique: We used real-time ultrasound elastography (RTE), or strain elastography (SE), or free-hand elastography which is the most widely available type of Ultrasound SE. Pressure was applied using the hand held US transducer which results in an elastogram. This is represented as a color coded image superimposed on the B-mode image, displayed next to it on the screen. In general, a rectangular, elliptic or round region of interest (ROI) was used to include the nodule with the surrounding normal thyroid tissue. We did a qualitative and a semiquantitative assessment of nodule elasticity by this method.

Philips IU 22 and Philips Affinity 70 Ultrasound machines were used. Written and informed consent was taken from the patient. The patient's clinical history and investigation findings were recorded.

The efficiency and accuracy of ultrasonography and elastosonography in differentiating benign from malignant nodules was determined and the results were compared with FNAC/histopathology findings, which was the reference standard. A "cut off " of 35\% was used as the most realistic rate of growing nodules based on previous researches to exclude benign nodules from undergoing FNAC.

\section{STATISTICAL ANALYSIS}

The collected data was coded and entered in Microsoft Excel sheet. The data was analysed using SPSS (Statistical Package for Social Sciences) version 20.0 software. The results were presented in tabular and graphical format. For Qualitative data various rates, ratios and percentage (\%) were calculated. Fischer test and chi square test with $\mathrm{P}$ value $<0.05$ were considered significant. For Quantitative data Mean, Median etc.

\section{RESULTS}

The present study was performed during a period of 2 years from August 2015 to August 2017. 50 patients were evaluated using grey-scale ultrasonography and elastography and findings were correlated with the histopathology results. The median age of patients was 50 years (range 22-85). The prevalence of nodules was lower in men (14\%) (Table 3).

Incidence of nodules was highest in the fourth decade, with a higher incidence amongst females. The youngest subject was a 22 year old female and the oldest patient was a male aged 85 years. 39 (78\%) patients had benign nodules while $11(22 \%)$ had malignant nodules (Table 4).

The accuracy of grey scale USG was calculated to be $94 \%$ and the accuracy of elastography and combination of elastography and grey scale USG was $96 \%$ (Table 6,7).

\begin{tabular}{|l|l|l|}
\hline Category & Pattern & USG Features \\
\hline 1 & Normal Thyroid Gland. No focal lesion. & - \\
\hline 2 & Benign Nodules (0\% risk of malignancy) & One suspicious feature \\
\hline 3 & Probably benign nodules (<5\% risk of malignancy) & One or two suspicious features \\
\hline $4 a$ & Undetermined Nodules (5 to $10 \%$ risk) & Two suspicious features \\
$4 \mathrm{~b}$ & Suspicious Nodules (10 to $50 \%$ risk) & More than two suspicious features \\
$4 \mathrm{c}$ & Highly suspicious nodules (50 to $85 \%$ risk) & Three or more suspicious features \\
\hline 5 & Probably Malignant (>85\% risk) & Four or more suspicious features \\
\hline 6 & Biopsy Proven Malignancy & \\
\hline \multicolumn{2}{|c|}{ Table-1: TIRADS (Thyroid Imaging and Data Recording System) Classification ${ }^{3}$} \\
\hline
\end{tabular}

\begin{tabular}{|c|c|c|c|}
\hline Category & Elastic Pattern & Color Coding & Benign/Malignant \\
\hline 1 & Diffuse elastic pattern & Homogenous soft & \multirow[t]{2}{*}{ Benign } \\
\hline 2 & Almost entire elastic pattern & $\begin{array}{l}\text { Predominantly homogenous soft with minimal areas } \\
\text { of hard color }\end{array}$ & \\
\hline 3 & Mosaic & Soft and hard color with predominance of soft color & $\begin{array}{l}\text { High probability of benign } \\
\text { with slight possibility of being } \\
\text { malignant. }\end{array}$ \\
\hline 4 & Mosaic & Soft and hard color with predominance of hard color & \multirow[t]{2}{*}{ Malignant } \\
\hline 5 & No Strain & Diffusely hard & \\
\hline
\end{tabular}


The ROC curve analysis for elastographic strain indices revealed area under curve to be 0.9 . The cut-off value was 0.8. The sensitivity and specificity was $100 \%$ and $94.9 \%$

\begin{tabular}{|l|c|c|}
\hline Age (Years) & Male (\%) & Female (\%) \\
\hline $0-10$ & 0 & 0 \\
\hline $11-20$ & 0 & 0 \\
\hline $21-30$ & 0 & $6(12)$ \\
\hline $31-40$ & 0 & $7(14)$ \\
\hline $41-50$ & $1(2)$ & $12(24)$ \\
\hline $51-60$ & $2(4)$ & $7(14)$ \\
\hline $61-70$ & $3(6)$ & $9(18)$ \\
\hline $71-80$ & 0 & $1(2)$ \\
\hline $81-90$ & $1(2)$ & $1(2)$ \\
\hline \multicolumn{3}{|c|}{ Table-3: Age and Sex Distribution } \\
\hline
\end{tabular}

\begin{tabular}{|l|c|c|}
\hline Sex & Benign (\%) & Malignant (\%) \\
\hline Male & $5(10)$ & $3(6)$ \\
\hline Female & $34(68)$ & $8(16)$ \\
\hline Overall & $39(78)$ & $11(22)$ \\
\hline
\end{tabular}

Table-4: Sex-wise Distribution of Benign and Malignant nodules

\begin{tabular}{|l|c|c|}
\hline Modality & $\begin{array}{c}\text { Benign } \\
\text { Histopathology } \\
\text { Results }\end{array}$ & $\begin{array}{c}\text { Malignant } \\
\text { Histopathology } \\
\text { Results }\end{array}$ \\
\hline Grey Scale (TIRADS) & & \\
\hline 2 & 22 & 2 \\
\hline 3 & 16 & 5 \\
\hline $4 \mathrm{a}$ & 1 & 2 \\
$4 \mathrm{~b}$ & & 1 \\
$4 \mathrm{c}$ & & 1 \\
\hline 5 & 8 & \\
\hline Elastosonography & 22 & 1 \\
\hline 1 & 8 & 09 \\
\hline 2 & 1 & 1 \\
\hline 3 & & \\
\hline 4 & & \\
\hline 5 & & \\
\hline Table-5: Comparison of Sonographic and Elastographic evalua- \\
\multicolumn{2}{|r|}{ tion with Histopathology results: } \\
\hline
\end{tabular}

respectively with positive likelihood ratio of 19.5 (Table 6 and 7).

Nodules that scored 1 and 2 on elastography could be safely considered to be monitored without the need for FNAC. $60 \%$ of the nodules scored 1 and 2 on elastography. We considered that $35 \%$ nodules grow in time and the reduction of FNACs based on our study was $39 \%,(0.65=$ score that nodules do not grow x $0.60=$ nodules that scored 1 and 2$)$.

\section{DISCUSSION}

Ultrasound is an ideal modality in the work up of thyroid abnormalities as it can easily differentiate between thyroid nodules and other neck masses. Alternatively sonography may help confirm the presence of a thyroid nodule when the findings of physical examinations are equivocal. This has added a new dimension to the management of solitary nodule of the thyroid. Rodney J Butch et $\mathrm{al}^{5}$ stated that that the major use of thyroid scanning has been in identifying additional thyroid nodules when one of them is palpable.

Nirad Mehta et $\mathrm{al}^{6}$ opined that ultrasound of the thyroid is a reliable method for evaluation of solitary thyroid nodule when combined with FNAC.

John J. Cronan ${ }^{7}$ suggested that over the past two decades, widespread use of US and incidental imaging detection has contributed to an increased detection of thyroid nodules and a threefold increase in thyroid aspirates. To avoid unnecessary repeated US examinations and FNACs risk stratification tools were developed.

To detect thyroid carcinomas with gray-scale US with the best possible efficiency, four grey scale ultrasonography signs were described by Park et al. ${ }^{9}$ The four US signs corresponded to a taller-than-wide shape, irregular borders, marked hypoechogenicity, and micro-calcifications. They reported an initial sensitivity of 94\%; however, our study detected 91.1\% of all carcinomas. The sensitivity of the TI-RADS grey-scale score was $95 \%$ compared with histopathological results. On the other hand, to safely rule out malignancy and asserting that a nodule is benign, we found a very high NPV of $97.4 \%$ for TIRADS as well as elastography score. TI-RADS and sonoelastographic scoring has the ability to discard malignancy with a high probability. A total of $74 \%$ of all nodules was classified as probably benign (Table 1).

Park JY et $\mathrm{al}^{9}$ obtained odds ratios of thyroid ultrasonography

\begin{tabular}{|l|c|c|c|c|}
\hline Modality & $\begin{array}{c}\text { No. of True } \\
\text { Positives (a) }\end{array}$ & $\begin{array}{c}\text { No. of False } \\
\text { Positives (c) }\end{array}$ & $\begin{array}{c}\text { No. of False } \\
\text { Negatives (b) }\end{array}$ & $\begin{array}{c}\text { No. of True } \\
\text { Negatives (d) }\end{array}$ \\
\hline Grey Scale & 9 & 2 & 1 & 38 \\
\hline Elastosonography & 10 & 1 & 1 & 38 \\
\hline Combination of Grey Scale + Elastography & 10 & 1 & 1 & 38 \\
\hline \multicolumn{2}{|r|}{ Table-6: True Positives, False Positives, False Negatives and True Negatives for sensitivity, specificity and predictive values for grey } \\
scale and sonoelastography versus histopathology results:
\end{tabular}

\begin{tabular}{|l|c|c|c|c|c|}
\hline Modality & $\begin{array}{c}\text { Sensitivity } \\
(\mathbf{a} / \mathbf{a}+\mathbf{b})\end{array}$ & $\begin{array}{c}\text { Specificity } \\
(\mathbf{d} / \mathbf{c}+\mathbf{d})\end{array}$ & $\begin{array}{c}\text { PPV } \\
(\mathbf{a} / \mathbf{a}+\mathbf{c})\end{array}$ & $\begin{array}{c}\text { NPV } \\
(\mathbf{d} / \mathbf{b}+\mathbf{d})\end{array}$ & $\begin{array}{c}\text { Accuracy } \\
(\mathbf{a}+\mathbf{d} / \mathbf{a}+\mathbf{d}+\mathbf{c}+\mathbf{b})\end{array}$ \\
\hline Grey Scale & $90 \%$ & $95 \%$ & $81.8 \%$ & $97.4 \%$ & $94 \%$ \\
\hline Elastography & $90.9 \%$ & $97.4 \%$ & $90.9 \%$ & $97.4 \%$ & $96 \%$ \\
\hline Combination of Grey Scale + Elastography & $90.9 \%$ & $97.4 \%$ & $90.9 \%$ & $97.4 \%$ & $96 \%$ \\
\hline \multicolumn{4}{|r|}{ Table-7: Sensitivity, specificity and predictive values for grey scale and sonoelastography versus histopathology results } \\
\hline
\end{tabular}


findings indicative of malignancy and probability of malignancy for each nodule in 1694 patients who had USguided fine-needle aspiration biopsy. They then predicted the probability of malignancy by comparing the findings with results of cytology and histopathology. They characterised 12 aspects of thyroid nodules as seen on ultrasonography and developed an equation to predict probability of a nodule being malignant as indicated by the findings (TUS $=1$, benign; $\mathrm{TUS}=2$, probably benign; $\mathrm{TUS}=3$, indeterminate; TUS $=4$, probably malignant; TUS $=5$, malignant). There was a significant correlation between the cytological category and the TUS $=1$ through TUS $=5$ categories $(r=0.491, p$ $<0.001)$. Our study also revealed significant correlation between TIRADS and histopatholgical analysis among all categories $(\mathrm{p}<0.001)$ (Table 5).

In our study 22 (44\%) of the nodules were colloid goiters. These appeared predominantly echogenic, a few being hypoechoic. Nirad Mehta et $\mathrm{al}^{6}$ found the same in 119 patients.

Kwak JY et $\mathrm{al}^{10}$ in a retrospective study of 3674 focal thyroid nodules in 3414 consecutive patients devised an equation that calculated the probability of malignancy in thyroid nodules and found a significant association with malignancy. Solid component, hypoechogenicity, microlobulated or irregular margins, microcalcifications, and taller-than-wide shape were the features used for TIRADS scoring. As the number of suspicious US features increased, the probability and risk of malignancy also increased. Positive predictive values according to the number of suspicious US features had a significant correlation to malignancy $(p<.001)$. We also found a significant correlation in the mentioned grey scale ultrasonography features and malignancy $(\mathrm{p}<0.001)$.

Most common primary thyroid carcinoma accounts for $75-90 \%$ of all cases. Microcalcifications was one of the commonest feature. Hoang et $\mathrm{al}^{12}$ showed microcalcifications were strongly associated with malignancy and 29-59\% carcinomas showed microcalcifications. This range was based on the prior studies done to predict the association of microcalcifications with malignancy. In our study 6 (12\%) of the papillary carcinoma were seen and $45 \%$ of the malignant nodules showed microcalcifcations (Figure 3).

Simeone et $\mathrm{al}^{11}$ showed $16 \%$ of the lesion to have cystic degeneration. Our study showed $24 \%$ of the nodules to have cystic degeneration.

Horvath $\mathrm{E}$ et $\mathrm{al}^{8}$ published a prospective study correlating US findings and fine needle aspiration biopsy (FNAB) in 1959 lesions. The percentages of malignancy defined in the Breast Imaging Reporting and Data System were followed: TIRADS 2 (0\% malignancy), TIRADS 3 (<5\% malignancy), TIRADS 4 (5-80\% malignancy), and TIRADS 5 (>80\% malignancy). The TIRADS classification was evaluated at the third stage of the study in a sample of 1097 nodules (benign: 703; follicular lesions: 238; and carcinoma: 156). Sensitivity, specificity, positive predictive value, negative predictive value, and accuracy were $88,49,49,88$, and $94 \%$, respectively. Our study had sensitivity, specificity, positive predictive value, negative predictive value of 90, 95, 81.8 and 97.4\% (Table 6 and 7). Their specificity and PPV was slightly less probably due to the limited features used for TIRADS classification. Elastography was performed in thyroid nodules detected at gray-scale US, and the high diagnostic performances of combinations of suspicious gray-scale US features are validated through many previous studies as well as in our study. The diagnostic performance of elastography itself or a combination of elastography and gray-scale US was found to be superior to that of gray-scale US alone. In our study, sensitivities and specificities of the combination of suspicious gray-scale US features were similar to those of the Rago and Vitti ${ }^{13}$ and Asteria et al criteria, regardless of nodule size and presence of macro- or eggshell calcifications. A total of 67 patients with thyroid nodules were enrolled in this prospective study. Nodules were examined in these patients by US B-mode, US color-power-Doppler, and US-elastography. Nodules were subjected to fine-needle aspiration biopsy and patients with a reading of malignant or indeterminate had thyroid surgery. The final diagnosis was based on the cytology reading in those who did not have surgery and the histopathology reading in those who had surgery. US-elastography scores were based on four classes of tissue stiffness.17 nodules were malignant and 69 were benign. Sensitivity and specificity of the US-elastography for thyroid cancer diagnosis were 94.1\% (16/17) and 81\% (56/69), respectively. The positive and negative predictive values were $55.2 \%(16 / 29)$ and $98.2 \%$ (56/57), respectively. Our study had better PPVs as compared to this study, while sensitivity and specificity were similar. Sonoelastography was, thus useful in predicting thyroid malignancy as an adjunctive diagnostic tool to gray-scale US (Table 6 and 7,).

Bojunga et $\mathrm{al}^{14}$ performed a meta-analysis and inclusion criteria for studies were the use of FNA cytology histopathology of surgical specimens as the diagnostic reference standard and assessment of sensitivity and specificity of real time elastography (RTE). Eight studies that included a total of 639 thyroid nodules were analyzed. The overall mean sensitivity and specificity for the diagnosis of malignant thyroid nodules by RTE of the eight studies was $92 \%$ and $90 \%$, respectively. In our study the sensitivity of elastography was $90.9 \%$ and specificity was $97.4 \%$. Based on quantitative evaluation of Strain Ratio we had a sensitivity of $100 \%$ and specificity of $95 \%$ by ROC analysis. A hard nodule should always be thought of as highly suspicious of malignancy but low stiffness can also be encountered in carcinomas.

Unluturk et $\mathrm{al}^{15}$ noted a US elastography sensitivity of $78 \%$ and positive predictive value of $92.3 \%$ for the diagnosis of malignant thyroid which was slightly less than our study but in agreement with the efficiency of sonoelastography.

The combination of gray-scale US and elastography can be used in two separate ways. Firstly, it can increase sensitivity because it can detect a small percentage of carcinomas omitted by gray-scale alone. Trimboli et $\mathrm{al}^{16}$ used signs for detecting carcinomas that were identical to our group and reported a sensitivity of only $85 \%$ with gray-scale. This value increased to $97 \%$ when gray-scale was combined with elastography. In our study the combination was $90.9 \%$ when compared with grey scale alone (90\%) (Table 7).

Moon et $\mathrm{a}^{17}$ studied a total of 703 solid thyroid nodules. Findings at elastography were classified according to the Rago criteria and the Asteria criteria. The diagnostic performances of gray-scale US, elastography with Rago criteria, and 
elastography with Asteria criteria, and odds ratios (ORs) for predicting thyroid malignancy were compared using generalized estimating equation analysis. Of 703 nodules, 217 were malignant and 486 were benign. Sensitivity, negative predictive value (NPV) of grey-scale US for the 703 nodules were $91.7 \%, 94.7 \%$, respectively, and these values were higher than sensitivity of $71.7 \%$ and NPV of $79.1 \%$ for a combination of grey scale and sonoelastography. This study showed an inferior sensitivity and NPV for the combination grey scale and sonoelastography as our study had sensitivity, specificity, positive predictive value, negative predictive value of 90, 95, 81.8 and $97.4 \%$ (Table 6 and 7).

The nodules included particularly in the category of score 1 and 2 of elastography may be reliably regarded as benign and excluded from the FNAC program. We estimated that 39\% of our cases could be safely monitored without the need for FNAC analysis which was in agreement with the study done by Gilles Russ et al in 2013 where they estimated 33.8\% reduction in their FNACs.

The strengths of this study include the prospective design, the inclusion of all nodules under investigation, and a sample size large enough to allow for comparison with conventional US characteristics by multivariate analysis. Other investigations have suggested that strain elastography may be useful in the evaluation of thyroid nodules. Some of these studies included only a small subset of patients being evaluated for malignancy, so that the predictive values are not applicable to the general population of nodules.

This study had few limitations. First, the sonoelastography and B-mode sonography images were in the same scan plane due to the use of split-screen technology during the sonoelastographic evaluations. This evaluation form may cause an initial opinion bias based on B-mode sonography that might affect sonoelastographic comment. Second, we did not evaluate the inter-observer variability when scoring. Although the equipment used in our study had technology reflecting the degree of compression pressure during sonoelastographic examinations, the extent of appropriate compression that might vary from examiner to examiner and can influence the elasticity image.

\section{CONCLUSION}

The scoring method by using TIRADS and the external manual compression method by sonoelastography can potentially be helpful in the management of thyroid nodules and can increase non invasive screening of benign nodules.

\section{REFERENCES}

1. Gharib H, Papini E, Paschke R, Duick D, Valcavi R, Hegedüs L, Vitti P. American Association of Clinical Endocrinologists, Associazione Medici Endocrinologi, and European Thyroid Association medical guidelines for clinical practice for the diagnosis and management of thyroid nodules. Endocrine Practice. 2010;16(Supplement 1):1-43.

2. Ophir J, Cespedes I, Ponnekanti H, Yazdi Y, Li X. Elastography: A quantitative method for imaging the elasticity of biological tissues. Ultrasonic imaging. 1991;13(2):111-34.

3. Sánchez JF. TI-RADS classification of thyroid nodules based on a score modified according to ultrasound criteria for malignancy. Rev. Argent. Radiol. 2014;78(3):138-48.

4. Yerli H, Yilmaz T, Oztop I. Clinical importance of diastolic sonoelastographic scoring in the management of thyroid nodules. American Journal of Neuroradiology. 2013;34(3):E27-30.

5. Rodney J. Butch Radiologic Clinics North America 1985;23(4):111-2.

6. Nirad Mehta et al: Sonographic appearance of solitary thyroid nodules, IJRA 1994;4(4);207-211.

7. Cronan JJ. Thyroid nodules: is it time to turn off the US machines?. Radiology. 2008;247(3):602-4.

8. Horvath E, Majlis S, Rossi R, Franco C, Niedmann JP, Castro A, Dominguez M. An ultrasonogram reporting system for thyroid nodules stratifying cancer risk for clinical management. The Journal of Clinical Endocrinology \& Metabolism. 2009;94(5):1748-51.

9. Park JY, Lee HJ, Jang HW, Kim HK, Yi JH, Lee W, Kim SH. A proposal for a thyroid imaging reporting and data system for ultrasound features of thyroid carcinoma. Thyroid. 2009;19(11):1257-64.

10. Park SH, Kim SJ, Kim EK, Kim MJ, Son EJ, Kwak JY. Interobserver agreement in assessing the sonographic and elastographic features of malignant thyroid nodules. American Journal of Roentgenology. 2009;193(5):W416-23.

11. Simeone JF, Daniels GH, Hall DA, McCarthy K, Kopans DB, Butch RJ, Mueller PR, Stark DD, Ferrucci Jr JT, Wang CA. Sonography in the follow-up of 100 patients with thyroid carcinoma. American journal of roentgenology. 1987;148(1):45-9.

12. Hoang JK, Lee WK, Lee M, Johnson D, Farrell S. US Features of thyroid malignancy: pearls and pitfalls. Radiographics. 2007;27(3):847-60.

13. Rago T, Vitti P. Role of thyroid ultrasound in the diagnostic evaluation of thyroid nodules. Best Practice \& Research Clinical Endocrinology \& Metabolism. 2008;22(6):913-28.

14. Bojunga J, Herrmann E, Meyer G, Weber S, Zeuzem S, Friedrich-Rust M. Real-time elastography for the differentiation of benign and malignant thyroid nodules: a meta-analysis. Thyroid. 2010;20(10):1145-50.

15. Ünlütürk U, Erdoğan MF, Demir Ö, Güllü S, Başkal N. Ultrasound elastography is not superior to grayscale ultrasound in predicting malignancy in thyroid nodules. Thyroid. 2012;22(10):1031-8.

16. Trimboli P, Guglielmi R, Monti S, Misischi I, Graziano F, Nasrollah N, Amendola S, Morgante SN, Deiana MG, Valabrega S, Toscano V. Ultrasound sensitivity for thyroid malignancy is increased by real-time elastography: a prospective multicenter study. The Journal of Clinical Endocrinology \& Metabolism. 2012;97(12):4524-30.

17. Moon WJ, Jung SL, Lee JH, Na DG, Baek JH, Lee YH, Kim J, Kim HS, Byun JS, Lee DH. Benign and malignant thyroid nodules: US differentiation-multicenter retrospective study. Radiology. 2008;247(3):762-70.

\section{Source of Support: Nil; Conflict of Interest: None}

Submitted: 13-07-2019; Accepted: 17-08-2019; Published online: 15-09-2019 